\title{
The Effect of the Hydrolyzates of Keratin- and Collagen-Containing Wastes of Poultry Processing in the Diets for Broilers on the Cecal Microbial Community
}

\author{
Vladimir Ivanovich Fisinin, Irina Pavlovna Saleeva, Valery Semenovich Lukashenko, Larisa \\ Alexandrovna Ilyina, Andrey Georgievich Koshchaev, Yuri Andreevich Lysenko
}

\begin{abstract}
The use of new protein-rich animal-derived ingredients in the diets for modern commercial poultry is an urgent problem for the researchers. The wastes of poultry slaughter and processing can be used for the production of concentrated feed-grade protein ingredients after the short-term and intense thermal treatment in the thin layer and subsequent enzymatic hydrolysis. These wastes contain primarily keratin and collagen. The aim of the study presented was the investigation of the effects of these hydrolyzates of keratin- and collagen-containing wastes in diets for broiler chicks on the cecal microbial community. The study was performed in the vivarium of All-Russian Research and Technological Institute of Poultry on four treatments (50 birds per treatment) of Ross- 308 broilers reared on the floor to 38 or 49 days of age. Control treatment 1 was fed a diet with fishmeal (67\% of crude protein) as a source of animal protein. Treatment 2 was fed the same diet with keratin-derived additive (85.7\% of crude protein) as a substitution for the fishmeal; treatment 3 was fed the same diet as treatment 2 additionally supplemented with a probiotic containing live cultures of Bacillus subtilis, Lactobacillus paracasei and Enterococcus faecium; treatment 4 was fed the same diet as treatment 1 with a mixture of keratin- and collagen-derived additives (67.1\% of crude protein) as a substitution for the fishmeal and the same probiotic as treatment 3. The qualitative and quantitative composition of cecal microbiota was determined via molecular genetic terminal restriction fragment length polymorphism (T-RFLP) technique. It was found that keratinand collagen-derived feed additives rendered no negative impact on the intestinal microbiota. Cecal concentrations of beneficial (normal) species in the treatments fed experimental diets were higher in compare to the control treatment.
\end{abstract}

Revised Manuscript Received on December 30, 2019.

* Correspondence Author

Vladimir Ivanovich Fisinin*, Federal Scientific Center "All-Russian Research and Technological Institute of Poultry" of Russian Academy of Science, Sergiev Posad, Moscow Province, Russia.

Irina Pavlovna Saleeva, Federal Scientific Center "All-Russian Research and Technological Institute of Poultry" of Russian Academy of Science, Sergiev Posad, Moscow Province, Russia.

Valery Semenovich Lukashenko, Federal Scientific Center "All-Russian Research and Technological Institute of Poultry" of Russian Academy of Science, Sergiev Posad, Moscow Province, Russia.

Larisa Alexandrovna Ilyina, "Biotrof" LCC, St. Petersburg, Russia.

Andrey Georgievich Koshchaev, Kuban State Agrarian University, Krasnodar, Russia.

Yuri Andreevich Lysenko, Kuban State Agrarian University, Krasnodar, Russia.

(C) The Authors. Published by Blue Eyes Intelligence Engineering and Sciences Publication (BEIESP). This is an open access article under the CC BY-NC-ND license (http://creativecommons.org/licenses/by-nc-nd/4.0/)
Keywords: Broiler Chicks, Cross Ross-308, Keratin- And Collagen-Derived Feed Additives, Enzymatic Hydrolysis, Cecal Microbiota.

\section{INTRODUCTION}

Commercial broiler production is presently highly industrialized; the chicks are usually kept in closed poultry houses with regulated microclimate and automation of basic technological processes [1, 2].

The genetic selection of modern meat-type chicken results in increasingly high rates of metabolic processes [3]; the biological peculiarities of avian gastrointestinal tract (GIT) require adequate composition of the intestinal microbiota to achieve the effective feed digestion [4].

The development of microbial GIT communities starts as early as at the hatch [5-7]; microbes are entering GIT of chicks from the air. During the first 24 hrs after the hatch the microbial colonies in the crop are forming with subsequent movement down the GIT to the cecum; this movement is possible due to low acidity and peptic activity in the gizzard of newly hatched chicks. At 3 days of age the amount of microbial cells in the GIT rises 10 -fold; at 2 weeks of age the microbial community of the small intestine is fully stabilized in terms of species and their concentrations [8, 9].

Microbial GIT populations supply the host (a chick) with nutrients, vitamins, natural antibiotic compounds, proteins, hormones and other bioactive substances [10-13].

The composition of GIT microbiota is changing during the rearing of chicks depending on the microbial loads in the air of a poultry house, the stage of the intestinal development, regime of feeding, and feed quality [14].

Feed composition can render the drastic effects on the composition of GIT microbiota $[15,16]$; any change in feed composition can alter the ratios of concentrations of normal microbial species in the GIT. These alterations can negatively impact the metabolic processes in host and eventually decrease livability and productivity of broilers [17]. 


\section{The Effect of the Hydrolyzates of Keratin- and Collagen-Containing Wastes of Poultry Processing in the Diets for Broilers on the Cecal Microbial Community}

Early research of microbial communities in different ecosystems was related to the investigation of species which could be isolated and cultured on artificial nutritive mediums.

Our knowledge of the intestinal microbiota in animals and poultry was further expanded by the metagenomic methods which do not require cultivation of the microbial species [18, 19]. Another advantage of these techniques is related to the possibility of fast determination and identification of a larger range of species. These molecular genetic techniques are also allowing for the identification of interrelationships between the microbiota and host and the development of new feed additives improving the intestinal health [20,21] due to the possibility of detailed analysis of the composition of the microbiota and its metabolites [22, 23].

The intestinal microbial community in chicken is presently known to contain bacterial, fungal, unicellular, and viral species, totally more than 640 species [7, 24, 25]. All these species can be allotted to the following three groups: normal, opportunistic, and pathogenic.

Normal microbiota helps the digestive system of the growing chick to digest dietary nutrients and prevents colonization and proliferation of pathogenic species within the GIT. Opportunistic species (like E. coli) can prevail in the GIT in the cases of reduction of normal communities and can rapidly become pathogenic. Pathogenic species are the main source of the digestive disorders; their toxins can destroy the absorbing intestinal surface and enter the bloodstream resulting in different intoxications.

The microbial species can also be divided into two groups according to the location and behavior within the GIT: resident (obligate) species and transient (facultative) species. Obligate species can associate with the enterocytes in small and large intestine via mucin and bacterial polysaccharides forming the specific surface biofilm. This biofilm produces organic acids, hydrogen peroxide, lysozyme, bactericidal compounds; these agents interact with the transient species (both opportunistic and pathogenic) preventing the mixing of obligate microbiota with transient species [8].

The defensive function is one of the most important functions of GIT microbiota. Intestinal microbiota prevents the colonization of cells and tissues by exogenous pathogenic species and plays an important role in the immune function in host. Any change in the functionality of GIT can result in poor digestion, absorption, and assimilation of dietary nutrients, increase in the secretion of the digestive enzymes, disbioses, decrease in resistibility to certain diseases and overall productivity in poultry [17, 26].

Every segment of the GIT in poultry (oral cavity, crop, gizzard, small and large intestine) has its own specific microbial biocoenosis. The microbial population of the oral cavity is the most inconsistent in composition and heavily influenced by the input of exogenous microbiota with feed, water, and air. This community is dominated by lactic bacteria, fungi, and cocci.

The community in crop is dominated by lactic bacteria enhancing the digestion if feed and producing lactic acid which in turn increases the acidity of the digesta in proventriculus and gizzard.

Obligate part of the population in the small intestine is dominated by lactic bacteria, Enterococci, and propionate-producing bacteria; transient part is dominated by the coliforms, Clostridia, Eubacters, Fusobacters.

Obligate population of the large intestine is dominated by Bifidobacteria, lactic bacteria, and Bacteroides; transient segment is similar to that in the small intestine. However, total concentration of the microbiota in the large intestine is many times higher in compare to the small intestine [8].

Cecal population is the most abundant in compare to other GIT segments: 1010 - 1011 cells/g of digesta [27]. Cecal microbiota plays an important role in the digestion and participates in different functions related to the maintenance of host homeostasis [5, 28-30].

Modern molecular genetic methods developed and advanced to the present allow for the investigation of bacterial communities without restrictions. One of these methods is polymerase chain reaction (PCR) technique, in particular express analysis based on the terminal restriction fragment length polymorphism (T-RFLP) technique. It involves isolation, amplification, and sequencing of bacterial DNA with subsequent identification of the T-RFLP-grams using existing databases and "Fragment Sorter" software and complex analysis of the data using statistic (correlative and cluster), taxonomic, and ecological approaches [31].

This method was used in a range of studies which resulted in a multifaceted characterization of the intestinal microbiota in broiler chicks detailing certain important functional principles of this complex microecosystem [32, 33]. The importance of the intestinal microbiota for the productive performance in broilers is understood for many years; the intestinal microbiota is an integral part of many physiological processes and key factor for the host's metabolism affecting its nutrition and health [34, 35]. Modern molecular approaches allowed for the clarification of modes of action of modern bioactive feed additives via evaluation of the resulting alterations in the intestinal microbiota and host immune function. The use of these additives in commercial broiler nutrition is necessary for the improvement of intestinal health status and minimization of health-related risks [36]. The use of the T-RFLP technique in Russia has relatively brief history; in particular, in 2008 it was modified by "BIOTROF" Co. (Saint-Petersburg) for the studies on the microbiotas in poultry. This method can be used for early diagnostication of bacterial diseases. This technique can be also used for the evaluation of the effects of different dietary ingredients on microbial communities and elucidation of interrelationships between the microbiota and productive performance, and, therefore, can be useful for the targeted choice of feed additives for poultry [37]. 
The aim of the study presented was the investigation of the effects of protein-rich keratin- and collagen-derived additives on the cecal microbiota in broiler chicks [38, 39].

\section{MATERIALS AND METHODS}

The trial was performed in 2018 on four treatments of Ross-308 floor-housed broiler chicks (50 as-hatch birds per treatment) reared from 1 to 38 or 49 days of age under similar management conditions [40,41]. Sex ratios in all treatments were determined in the end of rearing. The birds were allotted to the treatments according to live bodyweight, body condition, and batches of eggs for incubation.

Control treatment 1 was fed a diet with fishmeal (67\% of crude protein, CP) as a source of animal protein. Treatment 2 was fed the same diet with keratin-derived additive (85.7\% of $\mathrm{CP}$ ) as a substitution for the fishmeal; treatment 3 was fed the same diet as treatment 2 additionally supplemented with a probiotic containing live cultures of Bacillus subtilis, Lactobacillus paracasei and Enterococcus faecium; treatment 4 was fed the same diet as treatment 1 with a mixture of keratin- and collagen-derived additives (67.1\% of CP) as a substitution for the fishmeal and the same probiotic as treatment 3 .

The cecal samples were taken from three birds per treatment for the analysis of cecal microbiota using T-RFLP technique. Total DNA was isolated from the samples using Genomic DNA Purification Kit (Fermentas, Inc., Lithuania) according to the producer's manual; after the separate isolation all three samples from each treatment were combined for the subsequent analysis. PCR amplification was performed on DNA amplifier Verity (Life Technologies, Inc., USA) using eubacterial primers $63 \mathrm{~F}$ (CAGGCCTAACACATGCAAGTC) with labeled 5'-end (fluorophore WellRed D4, Beckman Coulter, USA) and 1492R (TACGGHTACCTTGTTACGACTT) allowing for the amplification of the fragment of 16S rRNA gene in positions from 63 to 1492 (numeration is given for the $16 \mathrm{~S}$ rRNA gene of E. coli) in the regime as follows: $950 \mathrm{C}-3 \mathrm{~min}$ ( 1 cycle); 950C - 30 s, 550C - 40 s, $720 \mathrm{C}-60$ s (35 cycles), $720 \mathrm{C}-5 \mathrm{~min}$. Final concentration of total DNA in the solution was determined using fluorimeter Qubit and Qubit dsDNA BR Assay Kit (Invitrogen, Inc., USA) according to the producer's manuals. The fluorescent labeled amplicons of 16S rRNA gene were purified according to standard method. The restriction of DNA samples (30-50 ng) was performed using restrictases HaeIII, HhaI, and MspI (Fermentas, Inc., Lithuania) according to the producer's manual (during 2 hours at $370 \mathrm{C}$ ). The products of the restriction were precipitated by ethanol; after the addition of $0.2 \mu \mathrm{L}$ of molecular weight marker Size Standart-600 and $10 \mu \mathrm{L}$ of formamide Sample Loading Solution (Beckman Coulter, USA) the samples were analyzed on genetic analyzer CEQ 8000 (Beckman Coulter, USA) according to the producer's manual. The instrumental error of this analyzer does not exceed $5 \%$. Heights and areas of the peaks were calculated by Fragment Analysis software (Beckman Coulter, USA); phylotypes were identified with the error margin of 1 nucleotide and their concentrations in the microbial community was determined. The attribution of the bacteria to certain taxonomic groups was performed with the use of http://mica.ibest.uidaho.edu/trflp.php database.

The variance analysis of the results of the trial was performed using Microsoft Excel 2010 software with the significance levels as follows: * $-\mathrm{P}<0.05$; ** $-\mathrm{P}<0.01$; *** $\mathrm{P}<0.001$.

\section{RESULT AND DISCUSSION}

The comparative analysis of the composition of cecal bacterial community in broilers (Table 1) revealed certain differences related to the age (38 or 49 days of age) and diet composition; however, concentration of normal microbiota was relatively high in all four treatments.

The cellulolytic bacteria (Bacteroidetes, Ruminococcus, Eubacterium, etc.) dominated in the cecal microbial community in all four treatments, in accordance with modern concepts of the intestinal microbiota in poultry [42, 43]. According to the databases (GenBank, Ribosomal Database Project, Silva) phylums Firmicutes, Bacteroidetes and Proteobacteria are accounted for $90 \%$ of the GIT microbial population in chicken and turkey [44].

Avian GIT is characterized by the absence of endogenous enzymes hydrolyzing fiber and other non-starch polysaccharides (NSPs); the digestion of these substances in poultry is therefore driven exclusively by the cellulolytic microorganisms. The share of cellulolytic bacteria (Bacteroidetes, Ruminococcus, Eubacterium, etc.) in cecal microbial community at 38 days of broilers' age was extremely high, ca. $50 \%$. The least share of cellulolytic species was found in treatment 4 (47.34\%), the highest in treatment 3 (54.8\%), with 51.0 and $52.5 \%$ in tr4eatments 1 and 2, respectively. At 49 days of age the share of cellulolytic bacteria grew in all treatments to ca. 60\%; the increase was $11 \%$ in treatment 1 and $20-22 \%$ in treatments $2-4$. The interesting changes were found in the concentrations of certain species obligate for the avian intestine (lactic bacteria from Lactobacillus and Enterococcus geni, Bifidobacteria) and capable to the antagonistic exclusion of pathogenic species (including salmonellas, Protea, Staphylococci, coliforms, Pseudomonas, Streptococci) due to the release of volatile organic acids and bacteriocins [45].

The maximal share of lactic bacteria at 38 days of age was found in treatments 3 and 4 (са. 6\%). In control treatment 1 the share of these species was the least - 1.7\%), in treatment 2 $3.0 \%$. An insignificant decrease in the concentrations of these species was found in all treatments at 49 days of age.

The share of Bifidobacteria was low in treatments 1 and 2 (without a probiotic in their diets); in treatments 3 and 4 fed diets supplemented with a probiotic the share of this genus in cecal community grew 10-fold at 38 and 49 days of age.

The Bacilli species are known to render significant antimicrobial activity against pathogens and other advantageous properties like the hydrolysis of dietary carbohydrates. 
The Effect of the Hydrolyzates of Keratin- and Collagen-Containing Wastes of Poultry Processing in the Diets for Broilers on the Cecal Microbial Community

Table 1. Relative concentrations (\%) of microorganisms in cecal microbial community in broilers according to T-RFLP analysis

\begin{tabular}{|c|c|c|c|c|c|c|c|c|c|}
\hline \multirow[t]{2}{*}{ Microorganism } & \multirow[t]{2}{*}{ Functional role } & \multicolumn{4}{|c|}{38 days of age; treatments: } & \multicolumn{4}{|c|}{49 days of age; treatments: } \\
\hline & & 1 & 2 & 3 & 4 & 1 & 2 & 3 & 4 \\
\hline \multicolumn{10}{|c|}{ Normal species } \\
\hline $\begin{array}{l}\text { Cellulolytic bacteria (Bacteroidetes, } \\
\text { Ruminococcus, Eubacterium, etc.) }\end{array}$ & $\begin{array}{l}\text { «Beneficial» species hydrolyzing fiber, } \\
\text { NSPs. and other dietary carbohydrates }\end{array}$ & 51.03 & 52.47 & 54.76 & 47.38 & 56.94 & 64.15 & 67.01 & 56.89 \\
\hline Lactobacillaceae & $\begin{array}{l}\text { «Beneficial» species with antimicrobial } \\
\text { activity against pathogens }\end{array}$ & 1.70 & 2.92 & 6.05 & 5.92 & 1.65 & 4.25 & 5.41 & 5.20 \\
\hline Bacilli & $\begin{array}{l}\text { «Beneficial» species with antimicrobial } \\
\text { activity against pathogens and other } \\
\text { advantageous properties (hydrolysis of } \\
\text { dietary carbohydrates, etc.) }\end{array}$ & 1.07 & 1.98 & 2.10 & 2.67 & 1.41 & 1.08 & 1.81 & 1.48 \\
\hline $\begin{array}{c}\text { Selenomonas from } \\
\text { Veillonellaceae family }\end{array}$ & Decomposition of organic acids & 10.91 & 14.61 & 14.57 & 10.40 & 2.92 & 12.21 & 22.67 & 16.31 \\
\hline Bifidobacteriaceae & $\begin{array}{l}\text { «Beneficial» species with antimicrobial } \\
\text { activity against pathogens }\end{array}$ & 0.08 & 0.09 & 0.79 & 0.74 & 0.01 & 0.04 & 0.77 & 0.78 \\
\hline \multicolumn{10}{|c|}{ Opportunistic species } \\
\hline Actinobacteria & Certain species can cause actinomycoses & 3.34 & 3.75 & 3.34 & 3.56 & 3.55 & 3.37 & 1.84 & 3.01 \\
\hline Enterobacteriaceae & Certain species can cause gastroenterites & 1.72 & 2.06 & 1.45 & 2.78 & 3.36 & 2.27 & 0.21 & 0.69 \\
\hline \multicolumn{10}{|c|}{ Pathogenic species } \\
\hline Fusobacterium sp. & \multirow[t]{7}{*}{ Agents of different infectious diseases } & 1.67 & 0.00 & 0.88 & 0.42 & 4.08 & 0.41 & 0.75 & 0.00 \\
\hline Peptococcus sp. & & 2.99 & 1.83 & 1.99 & 2.43 & 1.17 & 1.48 & 0.81 & 1.61 \\
\hline Campylobacteraceae & & 0.11 & 0.00 & 0.03 & 0.24 & 2.15 & 0.60 & 0.17 & 0.76 \\
\hline Clostridium novyi Clostridium perfringens & & 0.74 & 0.88 & 0.44 & 0.00 & 0.56 & 0.31 & 0.02 & 0.08 \\
\hline Staphylococcus sp. & & 0.56 & 0.09 & 0.16 & 0.68 & 0.92 & 0.22 & 0.53 & 0.48 \\
\hline Pasteurellaceae & & 0.04 & 0.53 & 0.04 & 0.05 & 0.03 & 0.35 & 0.00 & 0.05 \\
\hline Mycoplasma sp. & & 0.49 & 0.45 & 0.43 & 0.00 & 0.68 & 0.20 & 0.67 & 0.87 \\
\hline \multicolumn{10}{|c|}{ Transient species } \\
\hline Pseudomonas sp. & Food-born microorganisms & 3.64 & 1.86 & 1.78 & 2.13 & 1.21 & 0.10 & 0.58 & 0.83 \\
\hline Non-cultivating bacteria & unclear & 14.83 & 13.62 & 13.12 & 15.12 & 11.30 & 6.00 & 3.82 & 10.57 \\
\hline
\end{tabular}

At 38 days of age the highest bacilli percentage was found in treatment $4(2.7 \%)$ the lowest in treatment $1(1.1 \%)$; in treatments 2 and 3 this percentage was intermediate (ca. 2\%). At 49 days of age the bacilli percentage in treatments 2-4 decreased 1.2-1.8 fold in compare to 38 days while in treatment 1 increased 1.3-fold.

The Selenomonas can transform organic acids to different beneficial compounds and actively participate in the host's metabolism. The share of Selenomonas (Veillonellaceae family) was high in all treatments. At 38 days of age maximal percentage of Selenomonas was found in treatments 2 and 3 (14.6\%); in treatments 1 and 4 this share was ca. $10.5 \%$. At 49 days of age the percentage of Selenomonas in treatments1 and 2 decreased 3.7- and 1.2-fold, respectively, in compare to 38 days, while in treatments 3 and 4 in increased 1.5-fold.

The opportunistic actinomyces (Actinobacteria phylum) frequently cause the distinctive inflammatory diseases (called actinomycoses) in animals, poultry, and human. The most popular actinomycosis-inducing agents are $A$. israelii, $A$. gerencseriae, $A$. naeslundii, $A$. viscosus, $A$. odontolyticus, $A$. meyeri, etc. The percentages of actinomyces at 38 days of age were $3.80 ; 3.75 ; 3.34$ and $3.60 \%$ respective to treatments $1-4$. At 49 days of age these percentages in treatments 2-4 decreased ca. 1.5-fold while in treatment 1 remained at the level of 38 days. Certain Enterobacters (Enterobacteriaceae family) can cause gastroenterites. At 38 days of age the percentage of Enterobacters was low in all treatments (from 1.5 to $3.4 \%$ ). At 49 days of age the percentage of Enterobacters in treatments 1 and 2 grew 2.0- and 1.1-fold, respectively, while in treatments 3 and 4 grew 7 - and 4 -fold, respectively.

Pathogenic Clostridia (C. botulinum, C. perfringens, $C$. noviy) cause clostridial enteritis, botulism, diarrhea; these species produce toxins inducing necroses of certain tissues and organs of the host including the intestine. The percentages of pathogenic Clostridia in all treatments at both ages were lower than $0.9 \%$.

Peptococci (Peptococcus sp.) also can cause certain diseases. At 38 days of age the share of peptococci in all treatments was relatively high: $5 \%$ in control treatment 1 and $2.0-2.5 \%$ in treatments 2-4. At 49 days of age this share decreased in all treatments: 4-fold in treatment 1, by 20; 40 and $65 \%$ in treatments 2-4, respectively.

Fusobacteria (Fusobacterium sp.) can cause necrobacterioses. In control treatment 1 percentage of fusobacteria was high and tended to grow with age (from 1.7 to $4.1 \%$, or 2.5 -fold). In treatment 2 fusobacteria were not detected at 38 days of broilers' age though at 49 days this genus presented in cecal microbiota $(0.41 \%)$. In treatment 3 there were no age-related changes in the concentration of fusobacteria. It's interesting to note that in treatment 4 the reduction in this percentage occurred to 49 days of age - from $0.42 \%$ at 38 days to zero.

\section{Pathogenic}

Campilobacteria (Campylobacteraceae family) causing gastroenterites were identified in almost all samples (excluding treatment 2 at 38 days of age); percentage of Campilobacteria tended to increase with age in all treatments. maximal percentage was found at 49 days in control treatment 1 (2.15\%).

Staphylococci (Staphylococcus sp.) are pathogenic for poultry due to the production of toxins and enzymes promoting the colonization of different host tissues and disturbing the activities of host cells which results in necrotic inflammations, festering, and further expansion of the toxicoinfection. 
According to our data, concentrations of Staphylococci in all treatments and ages were low (less than 1\%).

Pasteurellas (Pasteurellaceae family) also can cause certain poultry diseases. The percentages of pasteurellas in all treatments were low (no more than $0.5 \%$ ) and tended to decrease from 38 to 49 days of age.

Mycoplasms (Mycoplasma sp.) are causative agents of avian mycoplasmoses. At 38 days of age the percentage of mycoplasms was low in all treatments and tended to increase with age. Maximal growth was found in treatment 4 : from $0 \%$ at 38 days of age to $0.87 \%$ at 49 days, maximal contamination level in all four treatments.

The Pseudomonas were found in the food-borne transient segment of cecal microbiota. The percentages of Pseudomonas in all treatments and ages were relatively low (from 0.1 to $3.64 \%$ ).

In all treatments and ages certain non-cultivating species were detected with the shares varying from 3.82 to $15.12 \%$. These species could not be identified and studied via traditional microbiological methods (involving cultivation on artificial mediums) though their role in the digestion in poultry is not inevitably positive.

Our data on the qualitative and quantitative composition of cecal microbiota are in accordance with previously published data [46-48].

\section{CONCLUSION}

It can be concluded that keratin- and collagen-derived protein feed additives rendered no negative impact on the intestinal microbiota. Cecal concentrations of beneficial (normal) species in the treatments fed diets supplemented with these additives were higher in compare to the control treatment.

\section{ACKNOWLEDGMENT}

The study was financed by the Russian Science Foundation, grant 17-16-01028.

\section{REFERENCES}

1. V.I. Fisinin "Poultry Production in Russia: The Strategy of Innovative Development", Moscow, Russian Academy of Agricultural Sciences, 2009, pp. 129.

2. V.I. Fisinin, "The state and perspectives of poultry breeding innovative development until 2020", Meat industry, 7, 2019, pp. 22-27.

3. V.I. Fisinin, "Poultry industry in Russia in 2010: The state and the trends of strategic innovative development of the industry", In: Proc. 11th Intl. Vet. Congr. on Poultry, Moscow, 2011. P. 5-19.

4. V.I. Fisinin, "World and Russian Poultry Production: Realities and Future Challenges", Moscow, Khlebprodinform, 2019, p. 470.

5. E. Amit-Romach, D. Sklan, Z. Uni, "Microflora ecology of the chicken intestine using 16 S ribosomal DNA primers", Poult. Sci., 83, 2004, pp. 1093-1098.

6. J.J. Dibner, J.D. Richards, C.D. Knight, "Microbial imprinting in gut development and health", J. Appl. Poultry Res., 17, 2008, pp. 174-188.

7. G.C. Mead, "Microbes of the avian cecum: types present and substrates utilized”, J. Exp. Zool., 3, 1989, pp. 48-54.

8. V.I. Fisinin, G.Yu. Laptev, I.A. Egorov, A.A. Grozina, "Modern Concepts of Intestinal Microbiota in Poultry Fed Different Diets: Molecular Genetic Approaches”. Sergiev Posad, VNITIP, 2017, p. 263.

9. V.V. Radchenko, E.V. Ilnitskaya, A.S. Rodionova, T.M. Shuvaeva, Y.A. Lysenko, G.A. Plutakhin, A.I. Manolov, I.M. Donnik, A.G. Koshchaev, "Identification of autochthonous strains as a basis for the development of the therapeutic and profylactic probiotics", Russian Journal of Biopharmaceuticals, 8(1), 2016, pp. 3-12.
10. J. Salanitro, I. Fairchilds, Y. Zgornicki, "Isolation, culture characteristics, and identification of anaerobic bacteria from the chicken cecum", Appl. Microbiol., 27, 1974, pp. 678-687.

11. D. Stanley, R.J. Hughes, R.J. Moore, "Microbiota of the chicken gastrointestinal tract: influence on health, productivity and disease", Appl. Microbiol. Biotechnol, 98, 2014, pp. 4301-4309.

12. B.V. Tarakanov, "Methods of Investigation of Gastrointestina Microbiotas in the Productive Animals and Poultry", Moscow, 2006.

13. M.A. Timoshko, "Microflora of Gastrointestinal Tract of Productive Animals", Kishinev, 1990.

14. V.I. Fisinin G.Yu. Laptev, I.N. Nikonov, L.A. Ilyina, E.A Yildyrym,V.A. Filippova, N.I. Novikova, A.A. Grozina, T.A. Egorova, T.N. Lenkova, V.A. Manukyan, I.A. Egorov, "Poultry gastrointestinal microbiome changes during ontogenesis", Agric. Biol., 51(6), 2016, pp. 883-890.

15. S. Birger, "Function of the digestive system", J. Appl. Poultry Res., 23(2), 2014, pp. 306-314.

16. G.G. Mateos, R.M. Lázaro, I. Gracia, "Feasibility of using nutritional modifications to replace drugs in poultry feeds", J. Appl. Poultry Res. 11(4), 2002, pp. 437-452.

17. V.I. Fisinin, P. Surai, "Gut immunity in birds : Facts and reflections (review)", Agric. Biol., 4, 2013, pp. 3-25.

18. R.I. Amann, W. Ludwig, K.H. Schleifer, "Phylogenetic identification and in situ detection of individual microbial cells without cultivation", Microbiol. Rev., 59, 1995, pp. 143-169.

19. S.H. Park, S.I. Lee, S.C. Ricke, "Microbial populations in naked neck chicken ceca raised on pasture flock fed with commercial yeast cell wall prebiotics via an Illumina MiSeq Platform”, PLoS One, 11(3), 2016 e0151944.

20. Instructions on the Sanitary and Microbiological Control of Poultry Carcasses and Meat, Poultry Products, Eggs, and Egg Products. Moscow, 1990.

21. T. Maniatis, E. Frich, G. Sambrook, "Molecular Cloning". Moscow, 1984.

22. A.G. Koshchaev, Y.A. Lysenko, A.V. Luneva, A.N. Gneush, M.V. Aniskina, V.I. Fisinin, I.P. Saleeva, "Studying Biological Activity of Lactobacillus Hydrolysates", Journal of Pharmaceutical Sciences and Research, 10(10), 2018, pp. 2475-2479.

23. P.W.J.J. van der Wielen, D.A. Keuzenkamp, L.J.A. Lipman, F. van Knapen, S. Biesterveld, "Spatial and temporal variation of the intestinal bacterial community in commercially raised broiler chickens during growth", Microbiol. Ecol., 44, 2002, pp. 286-293.

24. E. Barnes, "The intestinal microbiota of poultry and game birds during life and after storage", J. Appl. Bacteriol, 46, 1979, pp. 407-419.

25. A.G. Koshchaev, Y.A. Lysenko, M.P. Semenenko, E.V. Kuzminova, I.A. Egorov, E.J. Javadov, "Engineering and development of probiotics for poultry industry", Asian Journal of Pharmaceutics, 12(4), 2018, pp. 1179-1185.

26. I.P. Saleeva, V.S. Lukashenko, A.G. Koshchaev, V.G. Volik, D.Y. Ismailova, "Quality of Broiler Chicken Meat with the Use of Various Methods of Growing", Journal of Pharmaceutical Sciences and Research, 10(11), 2018, pp. 2979-2984.

27. X.Y. Zhu, T. Zhong, Y. Pandya, R.D. Joerger, "16S rRNA-based analysis of microbiota from the cecum of broiler chickens", Appl Environ. Microbiol., 68(1), 2002, pp. 124-137.

28. G.L. Hold, A. Schwiertz, R.I. Aminov, M. Blaut, H.J. Flint, "Oligonucleotide probes that detect quantitatively significant groups of butyrate-producing bacteria in human feces", Appl. Environ. Microbiol. 69, 2003, pp. 4320-4324.

29. K.D. Kohl, "Diversity and function of the avian gut microbiota", J. Comp. Phys. B., 182(5), 2012, pp. 591-602.

30. B. Owens, L. Tucker, M. Collins, K. McCracken, "Effects of different feed additives alone or in combination on broiler performance, gut microflora and ileal histology", Br. Poult. Sci., 49(2), 2008, pp. 202-212.

31. G. Laptev, I. Nikonov, L. Kryazhevskikh, I. Egorov, "T-RFLP-analysis of intestinal microflora - basis choice of feed additives for poultry", Ptitsevodstvo, 9, 2010, p. 25.

32. J. Apajalahti, "Comparative gut microflora, metabolic challenges, and potential opportunities", J. Appl. Poultry Res., 14(2), 2005, pp. 444-453.

33. B.B. Oakley, H.S. Lillehoj, M.H. Kogut, W.K. Kim, J.J. Maurer, A Pedroso, M.D. Lee, S.R. Collett, T.J. Johnson, N.A. Cox, "The chicken gastrointestinal microbiome”, FEMS Microbiol. Lett., 360(2), 2014, pp 100-112. 

The Effect of the Hydrolyzates of Keratin- and Collagen-Containing Wastes of Poultry Processing in the
Diets for Broilers on the Cecal Microbial Community

34. M.H. Kogut, "The gut microbiota and host innate immunity: Regulators of host metabolism and metabolic diseases in poultry?", J. Appl. Poultry Res., 22(3), 2013, pp. 637-646.

35. T. Rinttila, J. Apajalahti, "Intestinal microbiota and metabolites implications for broiler chicken health and performance", J. Appl. Poultry Res., 22(3), 2013, pp. 647-658.

36. T. Roberts, J. Wilson, A. Guthrie, K. Cookson, D. Vancraeynest, J. Schaeffer, R. Moody, S. Clark, "New issues and science in broiler chicken intestinal health: Emerging technology and alternative interventions", J. Appl. Poultry Res., 24(2), 2015, pp. 257-266.

37. G.Yu. Laptev, "Metagenomic studies on the intestinal microbiota in chicken", In: Proc. XVII Conf. WPSA (Rus. branch) "Innovative Technologies and Their Implication in Commercial Poultry Production", Sergiev Posad, 2012, pp. 212-215.

38. A.G. Koshchaev, Y.A. Lysenko, A.A. Lysenko, A.V. Luneva, I.P. Saleeva, V.I. Fisinin, "Screening of microorganism symbiont strains as a base of probiotics for poultry industry", Journal of Pharmaceutical Sciences and Research, 9(8), 2017, pp. 1373-1379.

39. L.N. Skvortsova, A.G. Koshchaev, V.I. Shcherbatov, Y.A. Lysenko, V.I. Fisinin, I.P. Saleeva, S.F. Sukhanova, "The use of probiotics for improving the biological potential of broiler chickens", International Journal of Pharmaceutical Research, 10(4), 2018, pp. 760-765.

40. V.I. Fisinin, T.A. Stollyar, V.S. Lukashenko, "Manual on the Technology of Broiler Meat Production”. Sergiev Posad, VNITIP, 2008.

41. V.I. Fisinin, "Methods of Scientific and Commercial Research on Poultry Nutrition", Molecular Genetic Methods for Determination of Intestinal Microflora., VNITIP, 2013.

42. L.J. Broom, M.H. Kogut, "The role of the gut microbiome in shaping the immune system of chickens”, Vet. Immunol. Immunopathol., 204, 2018 , pp. $44-51$.

43. K.C. Lee, D.Y. Kil, W.J. Sul, "Cecal microbiome divergence of broiler chickens by sex and body weight", J. Microbiol., 55(12), 2017, pp. 939-945.

44. S. Wei, M. Morrison, Z. Yu, "Bacterial census of poultry intestinal microbiome”, Poult. Sci., 92(3), 2013, pp. 671-683.

45. C. Gaspar, G.G. Donders, R. Palmeira-de-Oliveira, J.A. Queiroz, C. Tomaz, J. Martinez-de-Oliveira, A. Palmeira-de-Oliveira, "Bacteriocin production of the probiotic Lactobacillus acidophilus KS400", AMB Express, 8(1), 2018, p. 153.

46. J. Nanjundan, R. Ramasamy, S. Uthandi, M. Ponnusamy, "Antimicrobial activity and spectroscopic characterization of surfactin class of lipopeptides from Bacillus amyloliquefaciens SR1”, Microb. Pathog., 128, 2019, pp. 374-380.

47. V.A. Torok, R.J. Hughes, L.L. Mikkelsen, "Identification and characterization of potential performance-related gut microbiota in broiler chickens across various feeding trials", Appl. Environ. Microbiol., 77(17), 2011, pp. 5868-5878.

48. M. Witzig, A. Camarinha-Silva, R. Green-Engert, K. Hoelzle, E. Zeller, J. Seifert, L.E. Hoelzle, M. Rodehutscord, "Correction: spatial variation of the gut microbiota in broiler chickens as affected by dietary available phosphorus and assessed by T-RFLP analysis and 454 pyrosequencing", PLoS One, 10(12), 2015, e0145588.

Larisa Alexandrovna Ilyina, Candidate of Biological Sciences, winner of

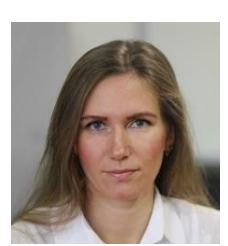
the Prize of the Government of the Russian Federation in the field of science and technology (2017), member of the World Scientific Association for Poultry. Employee of the Department of Large Livestock, St. Petersburg State Agrarian University. Published about 100 works.

Andrey Georgievich Koshchaev, Doctor of Biological Sciences, Professor

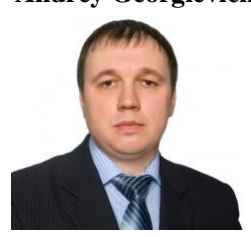
of the Department of Biotechnology, Biochemistry and Biophysics of the Kuban State Agrarian University. Published about 400 works

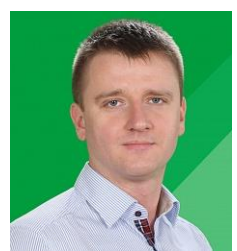

Yuri Andreevich Lysenko, Candidate of Biological Sciences, Associate Professor of the Department of Biotechnology, Biochemistry and Biophysics of the Kuban State Agrarian University. Published about 150 works.

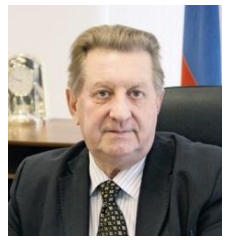

\section{AUTHORS PROFILE}

Vladimir Ivanovich Fisinin, Doctor of Agricultural Sciences, Professor, Academician of the Russian Academy of Sciences, prominent livestock specialist on the problems of industrial and breeding poultry farming, organizer of agricultural science. Author of over a thousand scientific publications in the field of poultry farming.

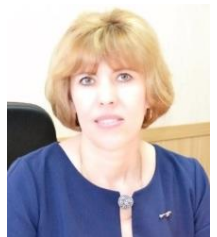

Irina Pavlovna Saleeva, Doctor of Agricultural Sciences, Professor of the Russian Academy of Sciences, Corresponding Member of the Russian Academy of Sciences, Chief Researcher, Head of the Laboratory for Meat Production Technology, Federal Scientific Center "All-Russian Scientific Research Institute of Poultry Farming".

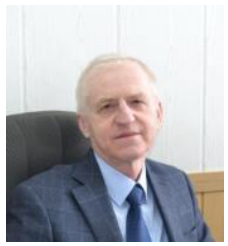

Valery Semenovich Lukashenko, Doctor of Agricultural Sciences, Professor, Laureate of the RF Government Prize in Science and Technology for (2003), member of the World Scientific Association for Poultry Farming. Published over 200 works. 